\title{
THE INFLUENCE OF ASPECT ON THE DISTRIBUTION OF SUGAR MAPLE
}

\author{
By M. R. CATER 1
}

Maxwell R. Cater was born in 1934 in Grand Falls, Newfoundland, received his B.Sc. in forestry from the University of New Brunswick in 1960 , and is presently working as a Graduate Assistant with the Department of Forestry, Maritimes District, Fredericton, N.B.

\section{ABSTRACT}

A study of hardwood distribution in northwestern New Brunswick indicates that sugar maple is most commonly found on easterly slopes. Several possible explanations are discussed, but none accounts for a difference in species distribution between easterly and westerly slopes.

\section{INTRODUCTION}

It is widely believed that plant species in the northern hemisphere requiring a warm climate will extend their range farther on south and southwest slopes than on the other aspects (Oosting 1953, Daubenmire 1959). If this is true, it should apply to sugar maple ${ }^{2}$ at the northern limit of its range. However, preliminary observations on the distribution of sugar maple in northwestern New Brunswick indicated no such relationship for southerly slopes. A survey was therefore undertaken to determine whether sugar maple distribution was influenced by slope direction.

The consistent relationships between species distribution and topography in the Green River area of New Brunswick are impressive. Sugar maple, red maple, the yellow and white birches, and beech are generally found on the hilltops and upper slopes in pure broadleaf stands. The white, red and black spruces, and balsam fir occur mostly on lower slopes and valley flats. Balsam fir, yellow birch, red maple, white spruce, and some sugar maple are found in mixtures on the middle slopes.

The underlying bedrock is remarkably uniform for over 40 miles in all directions and consists mainly of slate and argillite. These have a strong vertical cleavage which permits deep rooting and good drainage. Silt-loams cover the hilltops and slopes. They offer little variability and extensive examination and mapping indicate that there is no correlation between topography and soil. There is no regular pattern of skewness apparent in the shape of the hills.

The climate of northwestern New Brunswick has been described as continental (Putnam 1952). Maritime-Arctic air predominates during the summer, but Maritime-Tropical air masses penetrate frequently. The humid air combined with the irregular relief and elevations of up to 2,000 feet above sea level result in frequent precipitation and low cloud. At the Green River Laboratory the annual precipitation is 42 inches, with a frost-free period of approximately 60 days.

\footnotetext{
${ }^{1}$ Research Officer, Forest Research Branch, Department of Forestry, Maritimes District Office, Fredericton, N.B.

${ }^{9}$ Nomenclature as in Native Trees of Canada 5 th ed. 1956. Department of Northern Affairs and National Resources, Forestry Branch, Bulletin No. 61.
} 


\section{METHoDs}

Aerial photographs for the area provided a means for determining sugar maple distribution. This species predominates over all others in the tolerant hardwood stands, and has a large, full crown readily distinguished on aerial photographs. First, a type line was drawn around areas on each photograph in which tolerant hardwood crowns formed a closed canopy. An acetate overlay with two intersecting diagonal lines was then used to divide the photograph into four quarters. The intersection of the two lines was placed on the principal point of the photograph with the diagonals extending to the corners. Next, taking each quarter in turn, the point on the hardwood cover-type nearest the centre of the photograph was examined for its position on the slope and for the aspect. Position was measured as a percentage of the length of slope, 100 per cent being at the bottom. Cover-types observed to have had disturbance due to cutting were omitted. Two hundred and ten photographs were used; these covered an area of about 250 square miles.

\section{RESULTS}

The observations were summarized by aspect, and averages of the slope distribution of tolerant hardwoods computed for eight aspects. Sugar maple predominates over all others in the tolerant hardwood stands, and has a large, full crown readily distinguished on aerial photographs. These stands ranged from 20.9 per cent of the distance down slope on the northwest aspect to 51.1 per cent on the northeast, as indicated in Figure 1. This figure shows a hypothetical hill divided into ten parts representing percentage intervals down the slope. The total number of observations on each aspect indicates that tolerant hardwoods occur more frequently on southerly aspects than on any other, but that they extend farther down slope on the northeast and east aspects.

These results demonstrate that in areas where distribution is not determined primarily by bedrock pattern or soil types, unusual relationships of potential silvicultural importance are to be expected. The presence of hardwoods on only the tops of the hills could be explained by the occurrence of early frosts in the deep valleys, but the differences between aspects indicate that more than relative elevation is involved. It has been argued that because southerly slopes receive more radiation than north and east slopes, temperatures rise more rapidly in the spring, and broadleaf reproduction would flush too early. At the same time, reproduction on slopes sheltered from the sun would be retarded, and thus escape damage from late frosts. The findings reported here do not bear out this theory. No explanation for the difference between east and west aspects is immediately apparent.

\section{REFERENCES}

DAUBENMIRE, R. F. 1959. Plants and Environment. John Wiley and Sons, New York.

OOSTING, Henry J. 1953. The Study of Plant Communities. W. H. Freeman and Company, San Francisco, California.

PUTNAM, D. F. 1952. Canadian Regions. J. M. Dent and Sons (Canada) Limited, Toronto, Vancouver. 


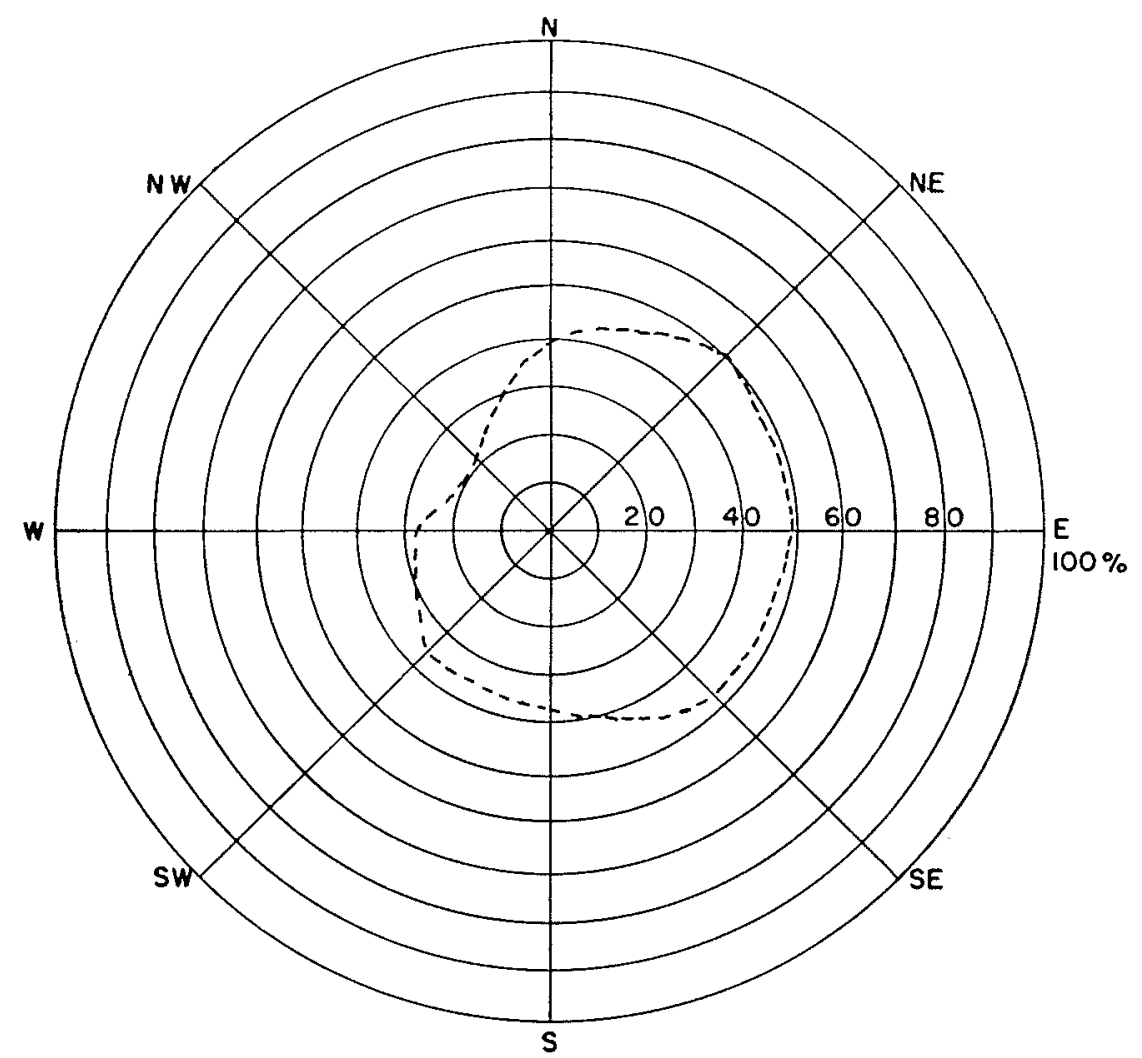

FIGURE 1. A hypothetical hill showing the distribution of hardwoods as observed by the sampling procedures used. The area enclosed by the dotted line represents the hardwood type. 